\title{
THE EFFECTS OF COGNITIVE STYLES ON NAÏVE IMPETUS THEORY APPLICATION DEGREES OF PRE-SERVICE SCIENCE TEACHERS
}

Received: 27 April 2012; Accepted: 5 June 2013

\begin{abstract}
The purpose of this study was to determine whether there is a relationship between pre-service science teachers' Field Dependent or Field Independent (FD/FI) cognitive styles and the application of degrees of naive impetus theory. The sample consisted of 122 preservice science teachers ( 97 females and 25 males) who were enrolled in the Introductory Physics course required by the Science Education program. Data were collected in two successive years, after the completion of the required Introductory Physics undergraduate courses, in 2008 and 2009. The Group Embedded Figure Test and Impetus Theory Application Test (a two-tier-type test) were administered to assess the FD/FI tendency of students and to determine the degree students applied the naïve impetus theory, respectively. Initial results showed that a majority of students had made use of the native impetus theory repeatedly. The results also indicated that the degree to which students applied the naïve impetus theory was statistically related to their FD/FI cognitive styles. The findings of this research showed that there existed a statistically significant difference between the FI and FD students' degree of applying the naïve impetus theory in favor of FI students. However, the test score gap between FI and FD students remained almost constant regardless of the testing instruments utilized in this study.
\end{abstract}

KEY WORDS: field independent/field dependent cognitive styles, naïve impetus theory, pre-service science teachers

\section{INTRODUCTION}

Studies in science education have indicated that students' conceptions about science often differ from the currently accepted scientific views. These ideas are commonly labeled as alternative conceptions (Clement, 1993; McDermott, 2001, Young-Jin, 2011). Some of these alternative concepts, as wrong as they are, exhibit a well-developed thinking structure, frequently grounded in everyday experiences. These misconceptions mainly originate from students' experience with the real world: they also provide viable and logical explanations for daily tasks. Another important source of students' alternative concepts comes from teachers who themselves exhibit similar alternative concepts and reflect these in their teaching. Additionally, textbooks have been reported as another important source of alternative concepts, especially when inadequate analogies and/or models are utilized to 
present the learning material (Driver, Guesne \& Tiberghein, 1985). Research has shown that students' alternative concepts can be very resistant to change and they also hinder meaningful learning of the correct scientific concepts (McDermott, 2001). For this reason, it is very important for science educators to learn about common alternative concepts that students have in science.

In recent years, many studies have been conducted to determine students' conceptual understanding and alternative concepts of specific topics in Physics, ranging from the simple notions treated in primary school science courses to the more sophisticated subjects addressed in calculus-based physics courses (Driver et al., 1985; Hestenes et al., 1992). McDermott (2001) has summarized findings of major studies conducted on students' conceptual understanding of physics concepts. Some of these can be classified as follows: (1) regardless of age and grade level, students have alternative conceptions; (2) university and high-school students have similar alternative conceptions; (3) alternative conceptions hinder meaningful learning; (4) traditional teaching methods do not foster meaningful learning; (5) traditional end-of-the-chapter-type problems are not sufficient to assess conceptual understanding; and (6) employing instructional strategies involving inquiry and/or conceptual change activities proved to be more promising in terms of helping students to construct scientific understanding of physics concepts.

Student understanding of key concepts on force and motion has also been extensively studied. The research has revealed that students hold many alternative conceptions and, hence, have difficulties in understanding the scientific concepts of force and motion. The literature indicates that students have the following major alternative conceptions regarding force and motion: motion implies force, confusion between position and velocity, confusion between velocity and acceleration, heavier objects fall faster, action-reaction pairs act on the same object, the dominance idea, and impetus theory (Hestenes et al., 1992).

\section{Studies about Naïve Impetus Theory}

Students' understanding or conceptualization regarding motion has received widespread attention in experimental psychology and physics education studies (Franco, 2004; Liu and MacIsaac, 2005; Kozhevnikov \& Hegarty, 2001; Hubbart, 2006, Franco, Muis, Kendeou, Ranellucci, Sampasivam \& Wang, 2012). A number of studies in the field of cognitive psychology have dealt with human perception as it relates to an object's movement. Results of these studies might provide further 
explanations of students' strongly held ideas about the impetus theory. These studies check students' responses on a memory task, which is accomplished by subconscious processes and based on an implicit perceptual knowledge of motion (Hubbart, 1993; Kozhevnikov \& Hegarty, 2001; Hubbart, 2006). The implicit perceptual knowledge of motion takes place through a continuous mental manipulated process known as "memory shift". The magnitude and direction of this memory shift is influenced by a number of factors. These factors have been listed as follows: velocity, trajectory, shape of object, context (i.e. frame of reference, moving or stationary background, and relative velocity), the period of discrepancy of the object and probing of a remembered location, and schematically proper ending and coherence of inducing a sequence (Hubbart, 1993; Kozhevnikov \& Hegarty, 2001).

Kozhevnikov \& Hegarty (2001) have summarized the major findings of these studies as follows. If a person views an object undergoing implied or apparent motion and the object suddenly disappears, memory for that object's final position is shifted forward in the direction of motion. They also summarized the general conclusion of these studies that the perceptual system embodies a principle analogous to physical momentum such as the continuing movement of an object until acted upon by a force. This phenomenon has been labeled as Representational Momentum (RM). According to results of RM research, there is not one unified understanding of the concept about motion, but rather we operate in a two-dimensional realm when dealing with motion: implicit perceptual knowledge of motion and explicit naïve verbal-cognitive concepts of motion.

Our implicit perceptual knowledge of motion resembles the historical impetus theory. RM research has also gathered evidence that an individual's implicit perceptual knowledge of motion may be "cognitively impenetrable". This last finding is in accordance with the numerous results of Physics Education Research (PER) and provides yet another explanation of why the impetus theory is heavily resistant to change.

On the other hand, a number of PER studies have examined and tried to explain students' responses based on a series of tasks where students were required to explicitly explain an object's trajectory of its motion. The results provided evidence that students mostly used the impetus theory to explain object motion. A general conclusion of PER studies on object motion is that many students hold alternative conceptions that are similar to the impetus theory. In particular, students think that a force applied to an object gives it an internal force (impetus) that serves to maintain the motion after the actual force has been withdrawn. Some students think that the internal force (impetus) dissipates over time due to 
the resistance of the medium causing the object to come to rest (Clement, 1981; Halloun \& Hestenes, 1985; Franco, 2004; Liu \& MacIsaac, 2005).

Studies conducted on students' alternative conceptions about force and motions have given clear evidence that students' explanations about motion are complex in nature and have similarities with the impetus theory (Trumper \& Gorsky, 1996; Kurger, Palacio \& Summers, 1992; Bogdanov \& Viiri, 1999; Franco, 2004; Liu \& MacIsaac, 2005; Bayraktar 2009). One of the first studies on students' utilization of impetus theory was conducted by Clement (1981). He provided strong evidence on the pervasiveness of this belief. More than $90 \%$ of the 150 college students that took part in this study used "invented forces" as the researchers named it (i.e. impetus) to describe the motions of a coin tossed into the air, and a rocket drifting in space from point $\mathrm{A}$ to $\mathrm{B}$, and then a constant force acting on it until point $\mathrm{C}$ where afterward this force was withdrawn. A study (Kurger, Palacio \& Summers, 1992) conducted on British primary school teachers' understanding of the concept of motion and force showed similar findings. Ninety-one percent of the teachers involved in the study believed in and used the impetus theory, rather than using Newton's Laws to explain the objects' motions. Furthermore, most of the teachers could not differentiate between force and momentum.

Liu \& MacIssac (2005) conducted a study on 614 university students registered in a calculus-based physics course. An important finding, as far as students' impetus theory was concerned, showed that students' impetus theories were independent of their academic achievement, the familiarity of the context, and the format of the questions. Bayraktar (2009) provides further findings regarding 79 Turkish pre-service physics teachers' alternative conceptions. Her study also showed that students made use of impetus theory to explain the motion of an object. She reported that about $70 \%$ of the students believed that a force was supplied through a "hit" and responsible for the object's motion afterward. Fifty-six percent of the students thought that an object could lose or gain impetus depending on the kind of interaction of the object with its surrounding, and $43 \%$ of the students explained a continual circular motion using the impetus notion. In summary, the use of the impetus theory was very widespread among students and seemed to be cross-cultural and gender independent.

\section{Studies about Field Independent/field Dependent Cognitive Styles}

Cognitive styles, i.e. preferred ways of selecting, perceiving, and processing new information, have been an active research area in science education (Witkin \& Goodenough, 1981; Johnstone \& Al-Naeme, 1991; 
Ates \& Cataloglu, 2007a, b). The general intent of cognitive style research is to identify and classify students' cognitive structures, compare them with the intended academic performance of students, and match them with instructional methods to better individualize learning.

The concept of cognitive style is about the idea of psychological differentiation, the root of which lies in the fact that individual's perceptions are affected by the surrounding conceptual field. This psychological differentiation is referred to as field independence and field dependence (Jonassen \& Grabowski, 1993, p488). Individuals that can easily break up an organized field and separate relevant information from its context or discern a "signal" (what matters) from "noise" (the incidental and peripheral) in a confusing background are defined as FI (Witkin \& Goodenough, 1981). Individuals that show difficulties in separating an item from its context are defined as field dependent (FD). Occasionally, FD/FI is also referred to as the global versus the articulated cognitive style (Jonassen \& Grabowski, 1993, p. 488). Basically, FI learners perceive and process information analytically, while FD learners do it in a global and passive way. Findings of previous studies indicated that learners who show greater FD were attentive to contextual and social information in the learning situation and tended to be responsive to the introduction of external reinforcement, either material or social. On the other hand, learners who could be categorized as FI tended to impose their own analytical structure on ambiguous material and ignored external influences (Witkin, Goodenough, Moore \& Cox, 1977; Frank, 1984).

The correlation between cognitive style and academic performance in various fields of science has been widely studied (Tinajero \& Paramo, 1997; Gray, 1997; Ziane, 1996; Johnstone \& Al-Naeme, 1991; Ates and Cataloglu, 2007a, b). The results mostly indicate that FI students score equally or higher than FD students in most of the academic fields. In the field of physics education, a few studies have been conducted to determine a possible relationship between cognitive style and physics achievement (Ziane, 1996; Karacam, 2005; Ates \& Cataloglu, 2007a). Ziane (1996) found that cognitive styles of students play an essential role in students' success in physics and FI physics students obtained higher scores in solving physics problems than the students who have a FD cognitive style. Karacam (2005) investigated the possible correlations between assessment techniques and conceptual understandings of the basic concepts of force and motion of high schools students with respect to different cognitive styles. In this study, students' conceptual understandings were assessed using three different test techniques (i.e. multiple-choice test, open-ended questions, and structural communication 
grids). The results of the study showed that there was a statistically significant difference between FI and FD students' conceptual understanding levels when assessed through multiple-choice test techniques, whereas the effect of students' cognitive styles of being field dependent/ field independent had no effect on the conceptual understanding level of students, using open-ended tests and structural communication grids techniques. Ates \& Cataloglu (2007a) investigated the possible relationship between students' FI/FD cognitive styles, problem-solving skills, and conceptual understandings in the area of force and motion. They found a statistically significant relationship between cognitive style and students' physics achievements. The findings of this research also illustrated that the relationship between cognitive style and students' physics achievements depended upon the operational definition of "physics achievement". They also showed that there exists a statistically significant difference between the FI and FD students' problem-solving skills in favor of FI students, but there was no statistically significant difference established between the groups for conceptual understanding.

\section{Purposes of the Study}

Most often physics teachers and researchers assess students' conceptual understandings either with the quantitative end of the chapter/unit problems found in common physics textbooks or multiple-choice tests developed by researchers. If students score relatively highly on these tests, it is assumed that the students had achieved a satisfactory level of understanding of the concepts presented in that course. However, a well-known study established that a high scoring student might still "lack" the desired understanding of fundamental concepts in physics. Therefore, one can claim that being able to solve standard problems in physics is not a true measure of the level of conceptual understanding (Clement, 1993; McDermott, 2001).

However, recent studies also showed that physics achievement and conceptual understandings of students depended upon several other factors, such as an operational definition of "physics achievement", assessment techniques, the types of problems, format of test techniques, and the context of the questions used in the research (Shepardson \& Pizzini, 1994; Sencer \& Eryilmaz, 2004; Karacam, 2005; Ates and Cataloglu, 2007a, b; Lawson et al., 2000). Clearly, the format of the assessment instrument affects the outcome.

Obscure problems with irrelevant information put FD students in a disadvantageous situation and will not contribute to furthering their 
understanding of the subject. Consequently, researchers need to explore alternative testing techniques regarding students' conceptions or alternative conceptions. Therefore, by using only the results of a multiple-choice test to determine students' alternative conceptions, we might run into the risk of attributing or labeling FD students as having alternative concepts while they might have had, for example, contextual problems.

If this is the case, then studies about determining a student's tendency for using the naïve impetus theory and a possible relationship between their cognitive style and conceptual understanding, which were previously determined by using a multiple-choice test, need to be reconsidered.

\section{Research Questions}

The following research questions framed this study:

1. Is there a difference between FI and FD students in their degree of applying the naïve impetus theory when assessed using a two-tier test?

2. Is there a difference between FI and FD students in their degree of applying the naïve impetus theory when assessed through only a multiple-choice test?

3. Is there an interaction effect between assessment techniques and cognitive styles of students in their degree of applying the naïve impetus theory?

\section{Methodology}

\section{The Sample}

The sample consisted of 122 freshmen and sophomore ( 97 females and 25 males) students enrolled in an introductory university physics taught for science teaching majors during the fall semesters of the first year of the undergraduate program at Abant Izzet Baysal University (AIBU) in Turkey.

\section{Procedure}

This research study was done over two successive years. After completing the introductory university physics course in the fall semesters (the years of 2008 and 2009), all students were administered the Group Embedded Figure Test (GEFT) and the Impetus Theory Application Test (ITAT) to assess the FD/FI tendency of students and determine the degree students 
applied the naïve impetus theory, respectively. The course was mostly traditional in format, having lectures, discussions, and solving standard end-of-chapter problems, but different teaching/learning techniques (i.e. analogies, inquiries, and conceptual change texts) were used a few times during the semesters to enhance teaching and learning. One of the researchers taught the course to all groups. He has approximately 20 years of teaching experience in high school and university-level introductory physics courses and contemporary courses in science education.

\section{Instrumentation}

The Group Embedded Figures Test (GEFT). The field dependent or field independent $(\mathrm{FD} / \mathrm{FI})$ tendencies of students were measured by using several instruments such as the Road and Frame Test, the Body Adjustment Test, and the Group Embedded Figures Test. All of these instruments involve the disembedding of a shape from its surrounding field. In this study, the Group Embedded Figures Test (GEFT) was used to determine students' levels of field dependency. The GEFT was devised and calibrated by El-Banna (1987) from Witkin's original tests materials (Witkin et al., 1977). Several researchers have used the GEFT and its validity and reliability has been established (Johnstone \& Al-Naeme, 1991). The procedure for the Turkish translation and its related validity and reliability study has been reported in a previous study (Ates \& Cataloglu, 2007a). The instrument includes 20 complex figures. It requires the students to recognize and identify a hidden simple shape in each of the set of complex figures. The students are required to outline it by pen or pencil on the lines of the complex figure. Before starting the test, students were briefed about the testing procedure and given $15 \mathrm{~min}$ to complete the test. Finding a correct shape embedded in a complex figure is scored one (1) point, and thus scores can range from 0 to 20 . The students who can correctly find more hidden figures are found to be better at the process of separation of a figure from a confusing background and are classified as being field independent (FI), and vice versa for being field dependent (FD). There is, of course, a continuum between these two extremes, and those of intermediate ability are classified as field intermediate (FINT).

El-Banna's formula was used to classify students as being FD, FINT, and FI (El-Banna, 1987). According to the researcher, students who scored more than one quarter of a standard deviation (SD) above the mean score were classified as FI, while students who scored under one quarter of a SD below the mean score were classified as FD, and between a score of plus or minus one quarter of a SD around the mean were considered as FINT. In this study, the same formula was used to classify 
students (El-Banna, 1987; Alamolhodaei, 1996; Ates \& Cataloglu, 2007a).

The Impetus Theory Application Test (ITAT). Recognizing the importance of students' understanding of the basic concepts in physics leads to developing valid and reliable instruments for assessing the conceptual understanding of students. Several tests, universal in the sense that they are limited to concepts that are addressed in introductory mechanics, were developed to assess students' conceptual understanding (Hestenes et al., 1992; Hestenes and Wells, 1992; Thornton and Sokoloff, 1998). The Force Concept Inventory (FCI), a very well-known and widespread multiplechoice instrument, was developed by Hestenes et al. (1992) to identify most common alternative conceptions and assess student understanding of the basic concepts in mechanics. The authors claim that the questions on the FCI were designed to be meaningful to students without formal training in mechanics to determine their preconceptions about Newton's Laws. Most of the multiple-choice distracters in the FCI are commonsense alternatives. Another important criterion while developing the FCI was that it should assess student understanding of the basic concepts in mechanics. The FCI is a popular instrument in physics education as it has been given to thousands of students at various levels (Hake, 1998). Hestenes et al. (1992) reported a taxonomy of commonsense alternative conceptions probed by the FCI. The taxonomy lists 28 distinct alternative conceptions along with corresponding inventory items that suggest their presence when selected. They have been grouped into six major commonsense categories such as kinematics, impetus, active force, action/reaction pairs, etc. In the impetus category, Hestenes et al. (1992) reported that impetus is perceived by students as an inanimate "motive power" or "intrinsic force" that keeps objects moving, which contradicts Newton's First Law. Evidence that students believe in some kind of impetus is therefore evidence that Newton's First Law is not fully understood. They also listed the distracters of the FCI items indicating the application by novices of the naïve impetus theory. There are 13 items related to the naïve impetus theory in the FCI.

As stated earlier, the purpose of this study was to assess students' conceptual understanding about motion, with a special emphasis on students' application levels of the naïve impetus theory. Since the format is affecting the outcome, the researchers have developed and used twotier tests to explore students' application levels of the naïve impetus theory in the present study. The use of two-tier tests allows teachers and researchers to not only understand students' conceptions or alternative conceptions but also to explore students' reasoning behind these ideas. 
Moreover, it facilitates assessment of alternative conceptions of a larger number of students in a more efficient and relatively easy way (Treagust, 1986; Odom \& Barrow, 1995).

Hence, we devised a new instrument that purposefully questions the application level of the naïve impetus theory. We used the Force Concept Inventory (FCI) and Mechanics Baseline Test (MBT) (Hestenes \& Wells, 1992) as our sources for constructing the Impetus Theory Application Test (ITAT). ITAT is a five-item two-tier test. Three of these questions were originally taken from FCI and the remaining two from MBT (see Appendix). Hence, ITAT inherits its content validity through FCI and MBT, described in the following section in some detail, and its reliability through a pilot study conducted on a sample of 152 pre-service science education teachers.

(a) Validity-Rational

For items of the ITAT, the Turkish version of the FCI and the MBT were used. Both the FCI and the MBT were translated and adapted into Turkish by Cataloglu (1996) and by Ates \& Cataloglu (2007a), respectively. The FCI utilized in this study has a published alpha reliability coefficient of 0.89 and a mean item difficulty of 0.35 . The MBT has a published alpha reliability coefficient of 0.70 and a mean item difficulty of 0.42 .

Additional evidence of validity can be provided through the correlation between the item scores of ITAT, FCI, and MBT. The FCI and MBT are extensively utilized instruments in our own teaching (Ates \& Cataloglu, $2007 \mathrm{a}, \mathrm{b}$ ). We found a correlation coefficient of 0.71 between previously administered FCI and MBT items as they related to ITAT. The resulting twotier test had five items assessing the application of the naïve impetus theory. Both the FCI and MBT tests are multiple-choice-type instruments. However, the ITAT (a modified two-tier test) measures students' understanding not only by distracter choice but also asks for further written explanations about students reasoning in choosing a particular answer. On the ITAT, there are five items related to the naïve impetus theory.

(b) Reliability

The following procedure was employed to determine the reliability of ITAT. First, a pilot study was conducted in the academic year of 2007. One hundred fifty-two pre-service science education teachers took part at the initial version of ITAT. The initial version consisted of six questions. Four of those questions were originally taken from FCI and the remaining two from MBT. Tables 1 and 2 show the statistical results of the pilot and final version of ITAT.

The initial results were promising, as the Cronbach alpha reliability was 0.79 for tier one (the multiple-choice part) and 0.69 for tier two. Both 
TABLE 1

Statistical results of the pilot study and final version for the ITAT

\begin{tabular}{|c|c|c|c|c|}
\hline \multirow[b]{2}{*}{ Statistics } & \multicolumn{2}{|c|}{ Values for pilot study } & \multicolumn{2}{|c|}{ Values for final version } \\
\hline & Multiple choice & Two-tier & Multiple choice & Two-tier \\
\hline$N$ & 152 & 152 & 152 & 152 \\
\hline Mean & 3.36 & 2.61 & 3.14 & 2.44 \\
\hline SD & 1.9 & 1.6 & 1.7 & 1.6 \\
\hline SEM & 0.15 & 0.14 & 0.14 & 0.13 \\
\hline Range & $0-6$ & $0-6$ & $0-5$ & $0-5$ \\
\hline Reliability & 0.79 & 0.69 & 0.79 & 0.67 \\
\hline Average point-biserial correlation & 0.68 & 0.61 & 0.74 & 0.65 \\
\hline Average difficulty index & 0.56 & 0.43 & 0.62 & 0.49 \\
\hline
\end{tabular}

values were satisfactory and well within the acceptable range. The test had a moderate difficulty level (0.56 and 0.43$)$. However, when further analysis was conducted per item, we observed that question number 2 was somewhat problematic (see table below).

As can be seen from Table 2, question 2 had a low item mean difficulty value of 0.16 and an associated relatively high standard deviation-clearly an outlier, hence leading us to conclude that this particular item was problematic. After conducting informal interviews with selected students, we came to the conclusion that this question was not well understood by the students. As a result, we opted to disqualify item number 2 from ITAT. Hence, the final version of ITAT is now made up of five questions. Table 1 shows the statistics of the final version of ITAT on the same sample without question number 2. Although the Cronbach alpha reliability coefficient remained the same (largely due to a large sample size), the average item difficulty

TABLE 2

Descriptive statistics for the ITAT items

\begin{tabular}{llllll}
\hline Question\# & $n$ & Min & Max & Mean & SD \\
\hline Q1 & 152 & 0 & 1 & 0.51 & 0.50 \\
Q2 & 152 & 0 & 1 & 0.16 & 0.37 \\
Q3 & 152 & 0 & 1 & 0.34 & 0.47 \\
Q4 & 152 & 0 & 1 & 0.51 & 0.50 \\
Q5 & 152 & 0 & 1 & 0.50 & 0.50 \\
Q6 & 152 & 0 & 1 & 0.60 & 0.49 \\
\hline
\end{tabular}


decreased from 0.56 to 0.62 for tier one and 0.43 to 0.49 for tier two, resulting in a more balanced test with respect to items that make up the test.

(c) Scoring

The scoring procedure of the ITAT was as follows: students were instructed to respond by checking the answer they thought was correct on the multiple-choice part and then provide a written rationale on their answer explaining their reasoning. If both the responses on the multiplechoice part and related explanations involved the application of the naive impetus theory, then we coded them as " 1 ". The responses and explanations which involved partial or non-naive impetus theory were coded as "0". Students' scores ranged from 0 to 5. Accordingly, the overall mean score for the test represents the naïve impetus theory application degree of students.

\section{Data Analysis and Results}

The Group Embedded Figures Test (GEFT) scores were analyzed to determine the FD/FI tendencies of students. The mean score of the students for the GEFT was 12.26 with a standard deviation of 4.01 . The formula mentioned in the previous section was used to classify students as being FD, FINT, or FI. According to this analysis, 56 students (46\%) scored between 0 and 11,13 students (11\%) scored 12 or 13 , and 53 students (43\%) scored between 14 and 20, and they were classified as FD, FINT, and FI, respectively. The percentages for the corresponding classifications of primary teaching department students in the same university were $40 \%$, $17 \%$, and $43 \%$ (Ates \& Cataloglu, 2007a). Hereafter, as reported earlier, the students classified as field intermediates (FINT) based on the scores in the GEFT were ignored to expose the extremes.

\section{Results on Research Question 1}

ITAT scores were analyzed to compare the groups' (FD and FI students) responses and mean scores for the degree of applying the impetus belief by using the two-tier test technique. ANOVA techniques were used to determine if the mean scores of the groups differed statistically. A summary and descriptive statistics for these analyses are presented in Tables 3 and 4, while an ANOVA table for ITAT mean scores by cognitive style is shown in Table 5.

FD and FI students' responses for each item of the ITAT were explored. As can be seen from Table 3, overall $54 \%$ of the students applied the naïve 
TABLE 3

Summary statistics of students' responses to the ITAT by cognitive styles

\begin{tabular}{|c|c|c|c|c|c|}
\hline \multirow[b]{2}{*}{ Questions } & \multirow[b]{2}{*}{$\begin{array}{l}\text { Cognitive } \\
\text { style }\end{array}$} & \multicolumn{2}{|c|}{$\begin{array}{l}\% \text { of students' responses } \\
\text { assessed by two-tier }\end{array}$} & \multicolumn{2}{|c|}{$\begin{array}{l}\% \text { of students' responses } \\
\text { assessed by multiple choice }\end{array}$} \\
\hline & & $\begin{array}{l}\% \\
\text { Misconception }\end{array}$ & $\begin{array}{l}\% \text { Total } \\
\text { misconception }\end{array}$ & $\begin{array}{l}\% \\
\text { Misconception }\end{array}$ & $\begin{array}{l}\% \text { Total } \\
\text { misconception }\end{array}$ \\
\hline \multirow[t]{2}{*}{ Q1 } & FD & 68 & 56 & 75 & 66 \\
\hline & FI & 43 & & 57 & \\
\hline \multirow[t]{2}{*}{ Q2 } & FD & 48 & 38 & 54 & 43 \\
\hline & FI & 26 & & 32 & \\
\hline \multirow[t]{2}{*}{ Q3 } & FD & 59 & 56 & 93 & 84 \\
\hline & FI & 53 & & 75 & \\
\hline \multirow[t]{2}{*}{ Q4 } & FD & 61 & 53 & 77 & 72 \\
\hline & FI & 45 & & 66 & \\
\hline \multirow[t]{2}{*}{ Q5 } & FD & 71 & 68 & 86 & 83 \\
\hline & FI & 64 & & 81 & \\
\hline \multirow[t]{2}{*}{ Overall } & FD & 61 & 54 & 77 & 70 \\
\hline & FI & 46 & & 62 & \\
\hline
\end{tabular}

impetus theory as measured by using the two-tier test technique. Sixty-one percent of FD students applied the naïve impetus theory, while only $46 \%$ of FI students applied the naïve impetus theory. The effects of FD and FI cognitive styles on students' mean scores for applying the naïve impetus theory in problem solving were also examined (Table 4). The FD students' mean score for the ITAT was 3.07 with a standard deviation of 1.3. The FI students' mean score was 2.32 with a standard deviation of 1.5 . The ANOVA results shown in Table 5 indicate that there was a statistically significant difference between FD and FI students in their degree of applying the impetus theory in favor of FI students.

TABLE 4

Descriptive statistics of ITAT scores by groups

\begin{tabular}{lllll}
\hline Test techniques & Cognitive styles & $N$ & Mean & $S D$ \\
\hline Two-tier test & FD & 56 & 3.07 & 1.3 \\
& FI & 53 & 2.32 & 1.5 \\
Multiple choice test & FD & 56 & 3.84 & 1.2 \\
& FI & 53 & 3.11 & 1.5 \\
\hline
\end{tabular}


TABLE 5

ANOVA table for ITAT mean scores by cognitive style

\begin{tabular}{llrlclr}
\hline Test & & \multicolumn{1}{c}{$S S$} & $d f$ & $M S$ & $F$ & P value \\
\hline ITAT two-tier & Between groups & 15.34 & 1 & 14.35 & 6.95 & $0.00^{*}$ \\
& Within groups & 220.8 & 107 & 2.1 & & \\
& Total & 235.2 & 108 & & & \\
ITAT multiple choice & Between groups & 15.3 & 1 & 15.3 & 7.5 & $0.00^{*}$ \\
& Within groups & 219.3 & 107 & 2.0 & & \\
& Total & 234.6 & 108 & & & \\
\hline
\end{tabular}

$* P<0.01$

\section{Results on Research Question 2}

As mentioned in the "Instrumentation" section, the ITAT was designed as a two-tier test and students were instructed to respond by checking the answer they thought was correct on the multiple-choice part of the test, and explain their reasoning on the second tier. Responses and explanations, if both had the reasoning of the impetus theory, were coded as " 1 ", for a possible total of five points. All other alternatives were coded as " 0 ". Our interest in this part of the study was to determine whether the possible relationship between FI and FD students in their degree of applying the impetus theory depended upon the methodology used to assess the application of the naïve impetus theory. In order to accomplish this task, students' answers were recorded only by evaluating the multiple-choice part of the ITAT. The same scoring principle was used.

Students' ITAT scores based on only the multiple-choice part were analyzed to compare the groups' (FD and FI) responses and mean scores for the degree to which students applied the naïve impetus theory. ANOVA techniques were used to determine if the mean scores of the groups differed statistically. Summary and descriptive statistics for these analyses are found in Tables 3 and 4, while the ANOVA table for the ITAT mean scores by cognitive style is shown in Table 5 .

The analyses on only the multiple-choice part of the two-tier ITAT showed that, overall, $70 \%$ of the students applied the naïve impetus theory. Overall, $77 \%$ of FD students applied the naïve impetus theory, whereas this percentage dropped to $62 \%$ for FI students. The effects of FD and FI cognitive styles on students' mean scores in their degree of applying the naïve impetus theory were also examined (Table 4). The FD students' mean score for the ITAT was 3.84 with a standard deviation of 
1.2. The FI students' mean score was 3.11 with a standard deviation of 1.5. The results from the ANOVA presented in Table 5 indicated that there was a statistically significant difference between FD and FI students in the degree of applying the impetus theory in favor of FI students.

\section{Results on Research Question 3}

The interaction effect between assessment techniques and cognitive styles of students in their degree of applying the naïve impetus belief were examined. Repeated measures ANOVA techniques were used to determine if there was a statistically significant interaction effect between test technique and cognitive styles on mean scores of the groups. A summary of the statistics and an ANOVA table for this analysis are found in Tables 4 and 6, respectively.

Results of analyses show that there was not a statistically significant interaction effect between assessment techniques and cognitive styles of students in their degree of applying the naïve impetus belief. For both test techniques, the FD students' mean score was higher than the FI students' mean score.

\section{Conclusions And Discussion}

The first aim of this study was to identify if there was a difference between field dependent and field independent students in the degree they applied the naïve impetus theory, by utilizing a two-tier test. In order to accomplish the task, the ITAT was adapted from the widely used tests FCI and MBT. The findings of this research showed that there exists a statistically significant difference between the groups in their degree of applying the naïve impetus theory in favor of FI students. The second aim of this study was to identify if there was a difference between field dependent and field independent students in the degree they applied the naïve impetus theory by assessing multiple-choice test techniques. The

TABLE 6

ANOVA table for ITAT mean scores by test techniques and cognitive styles

\begin{tabular}{lclrrr}
\hline Source & \multicolumn{1}{l}{$S S$} & $d f$ & \multicolumn{1}{c}{$M S$} & \multicolumn{1}{l}{$F$} & P value \\
\hline Factor 1 (two-tier $\times$ multiple choice) & 33.16 & \multicolumn{1}{l}{1} & 33.16 & 90.13 & 0.00 \\
Factor 1 $\times$ cognitive style & 0.008 & 1 & 0.01 & 0.02 & 0.88 \\
Error factor 1 & 39.35 & 107 & 0.37 & & \\
\hline
\end{tabular}


findings of this study also showed that there is a statistically significant difference between FD and FI students' levels of applying the naïve impetus theory in favor of FI students.

The results indicated that FI students performed significantly better than FD students in both assessment techniques. These results are consistent with previous research conducted on determining the relationship between physics achievement and cognitive styles which indicated that FI students score equally or higher than FD students in most of the academic fields. For example, Ziane (1996) found that the cognitive styles of students played an essential role in students' physics success, and FI physics students obtained higher scores in solving physics problems than those students who were classified as FD. While Ates \& Cataloglu (2007a) investigated the possible relationship between students' FI/FD cognitive styles, conceptual understandings, and problem-solving skills in the area of force and motion, they found a statistically significant relationship between cognitive style and students' physics achievements in favor of FI students.

One plausible explanation on why FI students tend to score higher than FD students is that when field dependents are confronted with problems, they find it difficult to locate the relevant information they are seeking because other information tends to mask what they are looking for (Jonassen \& Grabowski, 1993). On the other hand, typical end-of-chapter problems and/or achievement tests require problem-solving strategies that most often involve the differentiation between relevant and irrelevant information which FD students lack.

The third aim of this study was to examine a possible interaction effect between assessment techniques and cognitive styles of students in their degree of applying the naïve impetus theory. The findings of this research showed that there were no statistically significant interaction effects between students' cognitive styles and the format of the assessment technique (i.e. multiple-choice versus two-tier assessment) used to determine the degree of applying the impetus theory. For both assessment techniques, there existed a statistically significant difference between the groups in their degree of applying the naïve impetus theory in favor of FI students.

However, when the combined data (i.e. qualitative understanding and verbal explanations) of the two-tier-type diagnostic test were further analyzed regarding the possible relationship between students' conceptual understanding and their cognitive styles, we found the following results. While the gap between FI and FD students' scores reflecting the degree of applying the naïve impetus theory remained constant, the degree of 
applying the impetus theory increased by about $15 \%$ percent for both cognitive styles. That is, the two-tier test scores for both groups showed an increase in alternative conceptions regarding the impetus theory. As a result, assessing student's alternative conceptions regarding the impetus theory only through a multiple-choice type test tended to inflate students' test scores regardless of their cognitive styles. Therefore, for both groups, a more precise picture regarding the true nature of students' alternative conceptions was achieved through a two-tier-type test.

\section{Summary, Implications, AND Suggestions}

Our results are in general agreement with previous published research on the relationship between students' cognitive styles and their achievements. We found that FI students in general outperformed FD students with respect to applying scientific explanations on an object's movement. However, it should be stressed that a significant percentage of students in both groups still exhibited the native impetus theory while explaining the movement of an object or the reason for its sustainability of movement.

We found that when the students were given the opportunity to explain their reasoning for their answers, such as in a two-tier-type test, the overall percentage of students' scores dropped by about $15 \%$ when compared to multiple-choice test scores only. This result supports the previously raised concerns and limitations of a multiple-choice test when utilized in assessing students' cognitive understanding (Treagust, 1986; Odom \& Barrow, 1995). An interesting finding is that the test score gap between FI and FD students remained almost constant regardless of the testing instruments utilized in this study. More studies including different types of testing instruments need to be conducted to get a better understanding of the nature of cognitive styles and their possible relation to students' alternative conceptions.

One major limitation of our study could be contributed to by its teaching methods. The second major limitation of this study was the composition of the sample. The students involved in the study were predominantly female students. Hence, a similar study should be conducted with a more balanced gender distribution and be looking for the relationship between FI and FD students as it relates to applying the native impetus theory. 


\section{APPENDIX \\ The Impetus Theory Application Test (ITAT)}

Q1. A golf ball driven down a fairway is observed to travel through the air with a trajectory (flight path) similar to that in the description below.

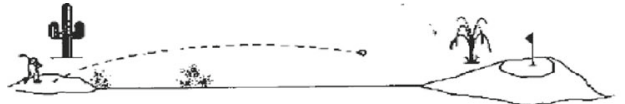

Which following force(s) is (are) acting on the golf ball during its entire flight? I. The force of the gravity II. The force of the 'hit' III. The force of the air resistance

a) Only I b) I and II c) I, II and III d) I and III e) II and III

Answer:

Please explain your reasoning.

Q2. A large box is being pushed across the floor at a constant speed of $4.0 \mathrm{~m} / \mathrm{s}$. If the force being applied to the box is suddenly discontinued, the box will;

a) Stop immediately

b) Continue at a constant speed for a very short period of time and then slow to a stop.

c) Immediately start slowing to a stop.

d) Continue at a constant velocity.

e) Increase its speed for a very short period of time, then start slowing to a stop

Answer:

Please explain your reasoning.

Q3. A boy throws a steel ball straight up. Disregarding any effects of air resistance. The force(s) acting on the ball until it returns to the ground is (are):

a) Its weight vertically downward along with a steadily decreasing upward force.

b) A steadily decreasing upward force from the moment it leaves the hand until it reaches its highest point beyond which there is a steadily increasing downward force of gravity as the object gets closer to the earth.

c) A constant downward force of gravity along with an upward force that steadily decreases until the ball reaches its highest point, after which there is only the constant downward force of gravity.

A constant downward force of gravity only.

e) None of the above, the ball falls back down to the earth simply because that is its natural action.

Answer:

Please explain your reasoning

Q4. The figure represents a multiflash photograph of a small ball being shot straight up by a spring. The spring, with the ball atop, was initially compressed to the point marked $\mathrm{X}$ and released. The ball left the spring at the point marked $Y$, and reaches its highest point at the point marked $Z$.

Which following force(s) is (are) acting on the ball during its entire flight?

I. The force of the gravity II. The force of the 'spring'

III. The force of the air resistance

a) Only I b) I and II c) I, II and III d) I and III e) II and III

Answer:

Please explain your reasoning

Q5. The diagram depicts a block sliding along a frictionless ramp. The eight numbered arrows in the diagram represent directions to be referred to when answering the question.

The direction(s) of the force(s) acting on the block (after leaving the ramp) at position III (its highest point), is (are) best represented by which of the arrow(s) in the diagram?

$\begin{array}{lllll}\text { a) Only } 5 & \text { b) } 4 \text { and } 5 & \text { c) } 5 \text { and } 6 & \text { d) } 5 \text { and } 7 & \text { e) } 3,5 \text { and } 7\end{array}$

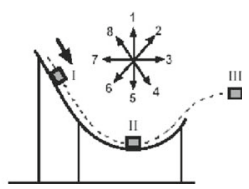

Answer:

Please explain your reasoning 


\section{REFERENCES}

Alamolhodaei, H. (1996). A study in higher education calculus and students' learning styles. Ph.D. thesis, University of Glasgow.

Ates, S. \& Cataloglu, E. (2007a). The effects of students' cognitive styles on conceptual understandings and problem solving skills in introductory mechanics. Research in Science and Technological Education, 25, 167-178.

Ates, S. \& Cataloglu, E. (2007b). The effects of students' reasoning abilities on conceptual understandings and problem solving skills in introductory mechanics. European Journal of Physics, 28, 1161-1171.

Bayraktar, S. (2009). Misconceptions of Turkish pre-service teachers about force and motion. International Journal of Science and Mathematics Education, 7, 273-291.

Bogdanov, S. \& Viiri, J. (1999). Students' understanding of the force concept in Russia and Finland. In M. Komorek, H. Behrendt, H. Dahncke, R. Duit, W. Graber, and A. Kross (Eds.), Proceedings of the second international conference of the ESERA, Kiel.

Cataloglu, E. (1996). Promoting teachers' awareness of students' misconceptions in introductory mechanics. M.Sc. thesis, METU, Ankara, Turkey.

Clement, J. (1981). Students' preconceptions in introductory mechanics. American Journal of Physics, 50, 66-71.

Clement, J. (1993). Using bridging analogy and anchoring intuitions to deal with students' preconceptions in physics. Journal of Research in Science Teaching, 30, 1241-1257.

Driver, R., Guesne, E. \& Tiberghein, A. (1985). Children's ideas in science. Philadelphia: Open University Press.

El-Banna, H. (1987). The development of a predictive theory of science education based upon information processing theory. Ph.D. thesis, University of Glasgow, Scotland.

Franco, A. B. (2004). Avempace, projectile motion and impetus theory. Journal of the History of Ideas, 64, 521-546.

Franco, G. M., Muis, K. R., Kendeou, P., Ranellucci, J., Sampasivam, L. \& Wang, X. (2012). Examining the influences of epistemic beliefs and knowledge representations on cognitive processing and conceptual change when learning physics. Learning and Instruction, 22, 62-77.

Frank, B. M. (1984). Effect of field independence-dependence and study technique on learning from a lecture. American Educational Research Journal, 21, 669-678.

Gray, C. (1997). A study of factors affecting a curriculum innovations in university chemistry. Ph.D. thesis, University of Glasgow.

Hake, R. (1998). Interactive-engagement vs. traditional methods: A six-thousand-student survey of mechanics test data for introductory physics courses. American Journal of Physics, 66, 64-74.

Halloun, I. \& Hestenes, D. (1985). The initial knowledge state of college physics students. American Journal of Physics, 53, 1043-1048.

Hestenes, D. \& Wells, M. (1992). A mechanics baseline test. Physics Teacher, 30, 159-166.

Hestenes, D., Wells, M. \& Swachhamer, G. (1992). Force concept inventory. Physics Teacher, 30, 141-153.

Hubbart, L. T. (1993). The effect of context on visual representational momentum. Memory \& Cognition, 21, 103-114. 
Hubbart, L. T. (2006). Bridging the gap: Roles and contributions of representational momentum. Psicologica, 27, 1-34.

Johnstone, A. H. \& Al-Naeme, F. F. (1991). Room for scientific thought. International Journal of Science Education, 13(2), 187-192.

Jonassen, D. H. \& Grabowski, B. L. (1993). Handbook of individual differences: Learning and instruction. Mahwah: Erlbaum.

Karacam, S. (2005). Determining the conceptual understanding levels of high school students' having different cognitive styles on major concepts of motion and motion laws by using different assessment techniques. M.A. thesis, Abant Izzet Baysal University, Turkey.

Kozhevnicov, M. \& Hegarty, M. (2001). Impetus beliefs as default heuristics: Dissociation between explicit and implicit knowledge about motion. Psychonomic Bulletin \& Review, 8, 439-453.

Kruger, C., Palacio, D. \& Summers, M. (1992). Surveys of English primary school teachers' conceptions of force, energy, and materials. Science Education, 76, 339351.

Lawson, A. E., Clark, B., Meldrum, E. C., Falconer, K. A., Sequist, J. M. \& Kwon, Y.-J. (2000). The development of scientific reasoning in college biology: Do two levels of general hypothesis-testing skills exist? Journal of Research in Science Teaching, 37, $81-101$.

Liu, X. \& MacIsaac, D. (2005). An investigation of factors affecting the degree of naïve impetus theory application. Journal of Science Education and Technology, 14, 101116.

McDermott, C. L. (2001). Oersted medal lecture 2001: Physics education research-The key to students learning. American Journal of Physics, 69, 1127-1137.

Odom, A. L. \& Barrow, L. H. (1995). The development and application of a two-tiered diagnostic test measuring college biology students' understanding of diffusion and osmosis following a course of instruction. Journal of Research in Science Teaching, 32, 45-61.

Sencar, S. \& Eryılmaz, A. (2004). Factors mediating the effect of gender on ninth-grade Turkish students' misconceptions concerning electric circuit. Journal of Research in Science Teaching, 41(6), 603-616.

Shepardson, D. P. \& Pizzini, E. L. (1994). Gender, achievement, and perception toward science activities. School Science and Mathematics, 94, 188-193.

Thornton, R. K. \& Sokoloff, D. R. (1998). Assessing students learning of Newton's laws: The force and motion conceptual evaluation. American Journal of Physics, 66, 228-351.

Tinajero, C. \& Paramo, M. F. (1997). Field dependence/field independence and academic achievement: A re-examination of their relationship. British Journal of Educational Psychology, 67, 199-212.

Treagust, D. F. (1986). Evaluating students' misconceptions by means of diagnostic multiple choice items. Research in Science Education, 16, 199-207.

Trumper, R. \& Gorsky, P. (1996). A cross-college age study about physics students' conceptions of force in pre-service training for high school teachers. Physics Education, 31, 227-236.

Witkin, H. A. \& Goodenough, D. R. (1981). Cognitive styles: Essence and origins field dependence and field independence. New York: New York University Press.

Witkin, H. A., Goodenough, D. R., Moore, C. A. \& Cox, P. W. (1977). Field dependent and field independent cognitive styles and their educational implications. Review of Educational Research, 47, 1-64. 
Young-Jin, L. (2011). Utilizing formative assessments to guide student learning in an interactive physics learning environment. Journal of Educational Technology Systems, $39,245-260$.

Ziane, J.H. (1996). The application of information processing theory to the learning of physics. Ph.D. thesis, University of Glasgow, Scotland.

\section{Erdat Cataloglu}

The Graduate School of Education

Bilkent University

06800 Bilkent, Turkey

E-mail: erdat.cataloglu@bilkent.edu.tr

\section{Salih Ates}

Department of Elementary Education, Faculty of Gazi Education

Gazi University

06500 Golkoy-Bolu, Turkey

E-mail: s.ates@gazi.edu.tr 
Copyright of International Journal of Science \& Mathematics Education is the property of Springer Science \& Business Media B.V. and its content may not be copied or emailed to multiple sites or posted to a listserv without the copyright holder's express written permission. However, users may print, download, or email articles for individual use. 